\title{
MONETARY POLICY RULES, POLICY PREFERENCES, AND UNCERTAINTY: RECENT EMPIRICAL EVIDENCE
}

\author{
Anton Muscatelli and Carmine Trecroci \\ University of Glasgow
}

\begin{abstract}
We survey recent empirical evidence on monetary policy rules, and find that the emphasis in the political economy literature on institutional design (e.g. central bank independence and inflation targeting) is exaggerated. Formal institutional reform seems neither a necessary nor a sufficient condition for the observation of shifts in monetary policy rules. However, there is no doubt that in some cases (e.g. the UK following the start of inflation targeting in 1992, and Bank of England Independence in 1997), a major shift in monetary policy conduct is detectable. We also highlight the problems in explicitly testing the predictions of the political economy literature. Semi-structural modelling approaches, such as time-varying VAR models may be more useful in understanding policy rules, and the interaction between policy shifts and changes in the transmission mechanism.
\end{abstract}

Keywords. Monetary Policy Rules; Central bank Independence; Inflation

\section{Introduction}

The strategic interactions between markets and policymakers, and in particular the credibility of macroeconomic policy, have been central to the policy debate in recent years. Institutional changes like the adoption of inflation targets, fixed or pegged exchange rate regimes, or the granting of an independent status to the central bank, are deemed to have important effects on an economy's performance.

The recent literature on monetary policy design has focused on three important aspects of macroeconomic performance in the industrialised economies in the last 30 years. First, the persistence of inflation even in absence of supply shocks and buoyant cyclical phases. Second, the degree of cross-country variation in average inflation rates. Third, the extent to which inflation control and the stabilisation of output and employment can be reconciled.

The focus of much of the literature has been on the role of policymakers in generating persistent inflation, and the problems in gaining credibility for inflation reduction. Figure 1 depicts annual CPI inflation rates and real ex post short-term interest rates in the G-3 economies over the period 1970-1999. While one can argue about the accuracy of ex post real rates as a measure of the actual 


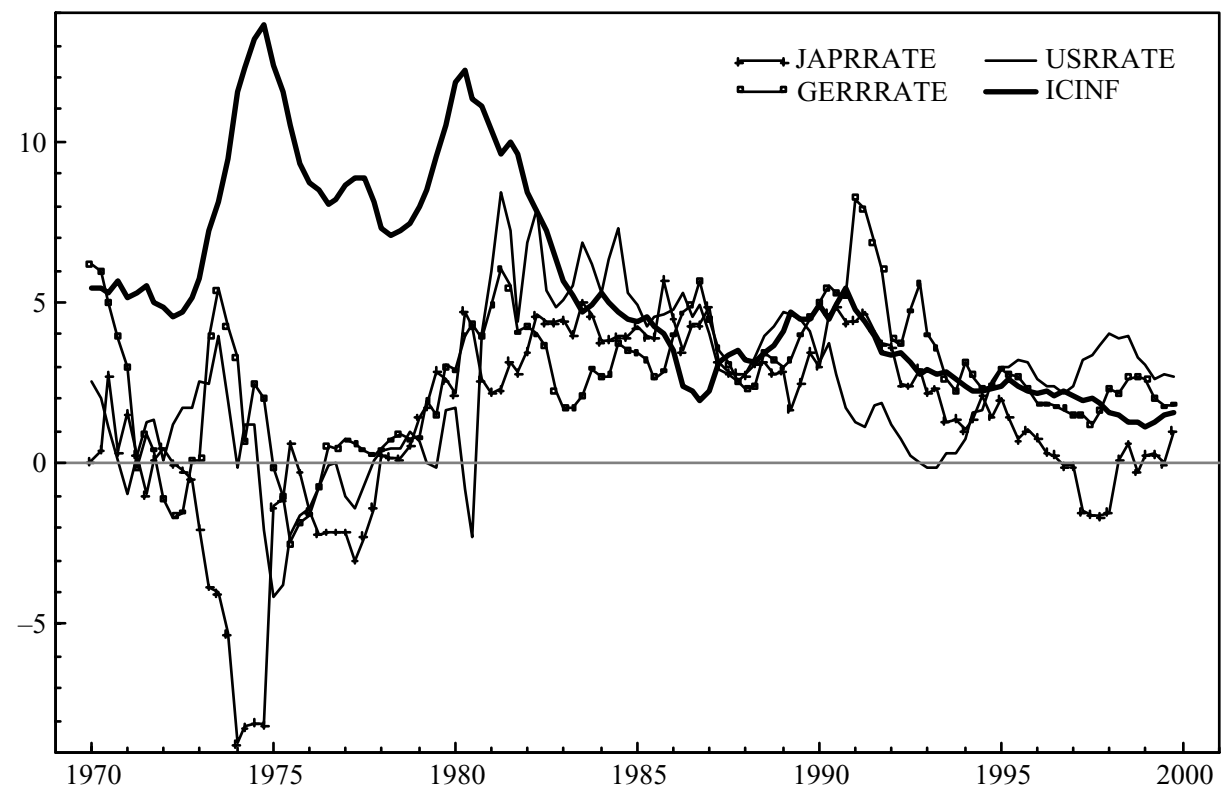

Figure 1. Real ex post short-term interest rates in USA, Germany and Japan, and annual CPI inflation in industrial countries, 1970-1999. Source: IMF, International Financial Statistics.

policy stance, the graph clearly shows a sharp break between the 1970s and the following decades. After 1980 real interest rates became invariably positive. Average inflation and inflation variability since the mid-eighties, and more dramatically after 1990 , follow a clear downward trend.

The explanation for the poor inflation performance of the 1970s is generally attributable to a conjunction of adverse supply shocks and unwillingness by the policy authorities to bring inflation under control given the prospects of sharp downturns in employment. What seems to have radically changed over the past two decades is a clear toughening of the monetary stance. How does monetary policy theory explain this change of gear in inflation control, and what role has institutional reform played in this process? This paper addresses this question in the light of recent empirical evidence on monetary policy behaviour.

As argued by Walsh (1998), two main results emerge from the theory of monetary policy design. First, it has highlighted the incentive structure which monetary authorities face. By doing so, these political-economy models have improved our understanding of observed inflation dynamics. Second, it has provided a strong argument in favour of restructuring incentive mechanisms and institutional arrangements to achieve macroeconomic stability. This has brought to the fore issues like transparency, accountability, and political independence in the design of policymaking institutions. 
This theoretical debate has taken place in a context of (and has contributed to) a period of intense institutional reform. The adoption of exchange rate targets, ${ }^{1}$ inflation targets, and the move towards greater central bank independence, are examples of major institutional change. Initially the literature on institutional reform emphasised the importance of central bank independence as a guarantee against sub-optimal policy outcomes (see for example Persson and Tabellini, 1999; Gärtner, this issue; Berger et al., 2001; Piga, this issue). More recently, the attention of the literature ${ }^{2}$ has switched to the design of optimal policy rules. That is, solving the classical policy problem: choosing the correct instrument settings to maximise the assumed policy objective function, subject to constraints on the economy's behaviour and the institutional setting. ${ }^{3}$

However, theoretical models of policy design, whilst generally useful, have not been without their problems. First, evaluating policy regimes through simple game-theoretic models of policymaker-private sector interactions is problematic given the partial-equilibrium nature of the theoretical models employed by much of the literature. Monetary policy-making in practice involves complex decisions, relying on a multitude of indicators and models (Blinder, 1998; Bank of England, 1999; Vickers, 1999). Important issues such as parameter (and indeed model) uncertainty are typically ignored by theoretical models. The validity of normative statements about the relative merits of alternative policy regimes and monetary rules is critically impaired by the limited nature of the theoretical models, as they only recently started to rely on empirical evidence.

The purpose of this paper is to survey the recent empirical evidence on monetary policy rules and its links with the theoretical literature on policy design. A complex picture emerges from empirical studies. As one would expect, there are important links between institutional reform and the conduct of monetary policy, especially in the 1980s and 1990s. But institutional change is neither necessary nor sufficient for the detection of shifts in monetary policy rules. Our central conclusion is that the emphasis that some researchers have placed on the invariance of policy rules in countries where institutions have been stable (see Clarida et al., 1998, Chinn and Dooley, 1997) is probably misplaced. The explanation is simple: theories of central bank independence place great importance on reputation building and the way in which the private sector learns about the central bank's intentions. In practice, however, the process of learning is a two-way one: central bankers have to adapt to a changing macroeconomic environment and will alter their policy responses as they learn about the uncertain environment in which they operate. Since the 1990s, especially given the prevalence of central bank independence as an institutional model, the private sector is no longer concerned with systematic inflation generated by a 'wet' policymaker. Its main concern is to understand what stimuli will trigger central bank responses and to respond rationally in its spending and pricing decisions.

The rest of the paper is organised as follows. Section 2 briefly surveys the key contributions to the political economy literature. We also look at early attempts to model the impact of institutional reform using cross-country evidence. Section 3 surveys the literature on single-equation policy reaction functions and the link

(C) Blackwell Publishers Ltd. 2000 
between these studies and the theoretical literature. In Section 4 our attention shifts to the multivariate framework, and the use of Vector Autoregressive (VAR) models to analyse monetary policy and to identify policy preferences. Section 5 concludes.

\section{Early empirical perspectives on monetary policy, credibility, and policy reforms}

\subsection{Introduction}

The importance of credibility considerations in monetary policy was first explicitly analysed by Kydland and Prescott (1977) and Barro and Gordon (1983). According to these models, and the large theoretical literature that ensued, the primary source of the 'credibility problem' lies in the short-run incentive that monetary authorities have in achieving an output (or employment) target above the NAIRU or market-clearing level. With such 'distorted' preferences, discretionary conduct of monetary policy will produce a positive inflationary bias, and no output gains. To overcome this sub-optimal outcome, society might delegate the conduct of monetary policy to an independent central banker (see Rogoff, 1985; Gärtner, this issue) whose preferences relative to output/inflation stabilisation are more 'conservative' than society's as a whole (or government's). In this case, inflation stabilisation would be traded off with output stabilisation: inflation control would be ensured at the cost of a less-than-optimal stabilisation of supply shocks.

In passing one should mention that the 'distorted preferences' story is a simplification, and that credibility problems can arise even in the absence of a long-run conflict of objectives between the policy-maker and the private sector (see Kydland and Prescott, 1977). The time-inconsistency problem also occurs in models where the policymaker is quite happy to stabilise the economy at the NAIRU, but where some key variables in the transmission mechanism (inflation itself, or more realistically long-term interest rates or the exchange rate) are forward-looking or 'jump' variables.

The answer to the time-inconsistency problem in either case is two-fold. First, reputational forces, supported by appropriate incentive mechanisms (al-Nowaihi and Levine, 1996) may mitigate the credibility problem. However, the usual argument against reputation-building on the part of an elected policymaker is that at some stage short-term considerations will dominate and will bring about a reversal to the Nash or discretionary solution. Second, an institutional solution can be found. A constitutional rule, or central bank independence combined with an optimal inflation contract (Walsh, 1998) or an optimal inflation target (Svensson, 1997a), could eliminate the time-inconsistency problem and reconcile inflation control with an optimal stabilisation policy (see Gärtner, this issue). Complications can still arise even with an independent central bank, because the central bank's preferences are not known with certainty leading to a 'democratic deficit' (see Muscatelli, 1998a, 1998b), or because the central bank has private 
information (Cukierman, 1992, Faust and Svensson, 2000). However, the institutional set-up can be designed to take account of these additional problems of accountability and transparency ${ }^{4}$ (see Muscatelli, 1999, Walsh, 1999, Faust and Svensson, 2000).

\subsection{Cross-country analyses of central bank independence and economic performance}

Grilli et al. (1991), Cukierman et al. (1992), and Cukierman (1992) were amongst the first to examine the empirical link between credibility and central bank independence $^{5}$ (CBI). In particular, these studies constructed several index measures of CBI, based on a wide set of institutional characteristics. Most of the OECD (and some non-OECD) countries' central banks were ranked according to these institutional, legal, and economic criteria. A subsequent revision and enrichment of these measures can be found in Eijffinger and de Haan (1996) (see also Berger et al., 2001).

Grilli et al. (1991) and Cukierman et al. (1992) compute cross-country correlations of the index measures of instrument and goal independence with several indicators of economic performance. One key hypothesis test was that economies with relatively more independent monetary authorities should have benefited from lower inflation rates. Their results showed that, at least in the advanced economies, a negative relationship between some measures of CBI and inflation could be found. A high degree of CBI appears to be quite clearly associated with low inflation. Moreover, economies with independent and conservative central banks apparently do not suffer from above-average output volatility. Grilli et al. found that CBI never exerts a significant role in explaining the level or the variability of output growth, in contrast to what one would expect following Rogoff's (1985) analysis. In the same vein, Alesina and Summers (1993) detected no significant relationship between $\mathrm{CBI}$ and the variability of several real variables like GDP growth and unemployment.

These simple cross-country results can be challenged on both methodological and technical grounds. First, most of the contributions tend to identify central bank independence with central bank conservatism (CBC). ${ }^{6}$ While a high degree of CBI usually implies a high degree of CBC, there might be important cases in which this is not the case. Second, one would ideally wish to examine the effects on economic performance of policy decisions, rather than of policy outcomes. The latter are clearly affected, even in the medium-run, by a host of factors other than the institutional arrangements.

Many of the cross-section studies omit control variables which might explain the cross-sectional distribution. There is also no scope to verify the direction of causality. In fact, Posen $(1993,1995)$ suggests that causality is more likely to run from low inflation to high CBI, rather than in the opposite direction. In other words, societies characterised by a stable economic environment (in terms of relatively low and stable inflation and output volatility) are likely to offer stronger political support for independent monetary institutions, which are, in turn, more

(C) Blackwell Publishers Ltd. 2000 
effective in controlling inflation. Consequently, countries where there is a greater degree of consensus on the benefits from low and stable inflation do tend to develop central banks that are more independent (see Muscatelli 1998b). Overall, the nature of monetary institutions in place results from a dynamic conflict of interests over output/inflation stabilisation policies (see Drazen, 2000).

Thus, the cross-sectional approach might lead to misleading conclusions. It omits country-specific features that might instead account for the observed crosssectional variation in inflation rates employment and output variability, and which are simultaneously correlated with the degree of independence granted to the central bank. ${ }^{7}$ Moreover, in contrast to the time series approach examined in Sections 3 and 4, the cross-section approach does not help our understanding of how structural and institutional change affects macroeconomic performance.

\section{Forecast-based monetary policy rules and central bank preferences}

With some notable exceptions, ${ }^{8}$ most theoretical analyses of policy rules employ static structural models. These make the models more tractable analytically, but they ignore the presence of uncertainty and lags in the monetary transmission mechanism.

Lags in the monetary transmission mechanism are a universally accepted empirical fact. Modern 'new neoclassical synthesis' macroeconomics combines short-run frictions with intertemporal optimising behaviour on the part of the private sector. Short run frictions are usually attributed to stickiness in pricesetting behaviour (Rotemberg and Woodford, 1999), or to rigidities in the money market (Christiano, Eichenbaum and Evans, 1997; Christiano and Gust, 1999). Unanticipated policy actions can therefore affect final goals only with some lag. While the response of real variables, like output and employment, to an unexpected monetary impulse materialises after some time, changes in such variables in turn will influence the price level after an additional lag.

This yields what appears to be a very traditional approach to monetary policy evaluation (see Blanchard, 1990). But the real innovation of the most recent wave of inter-temporal macromodels is that the optimising behaviour of private agents explicitly depends on what they expect about the future course of monetary policy. In other words, the private sector's beliefs about how monetary policy will operate in the future determines the extent to which real and nominal variables will respond to policy impulses. The equilibrium path of the economy is then found by determining the rational expectation of future policy actions under the constraint that monetary authorities will follow some fixed policy rule.

As an alternative to the fixed policy rule, optimising behaviour on the part of the monetary authorities can be built into these models. Some objective function can be postulated for the monetary authorities (e.g. minimising output/inflation deviations from some desired value), and one can derive the optimal policy rule with the private sector's expectations taken as given. Another alternative is that optimal rules can be derived if the monetary authorities can feasibly pre-commit 
to a path for the policy instruments. However, this second alternative requires the consideration of whether the central bank has some precommitment technology.

A number of contributions have extended the simple static models of policy design to dynamic structural optimising models which embody monetary transmission lags (Svensson, 1997b, 2000; Amato and Laubach, 1999; Batini and Haldane, 1999; Goodhart, 1999; Rudebusch and Svensson, 1999; Svensson and Woodford, 1999; Onatski and Stock, 2000). These contributions focus on two essential points. First, the forward-looking nature of private agents' behaviour implies that welfare can be maximised by stabilising the monetary authorities' forecast of inflation around the appropriately chosen target, at some horizon. Second, central banks can rein in actual inflation by adjusting interest rates in order to stabilise the inflation forecast, and in doing so they can also reduce output variability. Interest rates must be set, in practice, to minimise the departures of forecast inflation at a specific horizon from the assumed target value.

In the light of this, the crucial aspects of policy formulation are:

(a) the choice of indicators used to formulate inflation forecasts;

(b) the appropriate choice of the inflation target (i.e. whether it should be a point, a corridor, an asymmetric range) and the price index on which it should be defined; and

(c) the horizon over which the forecast is stabilised around the target level.

For instance, the European Central Bank's monetary policy strategy explicitly argues that the objective of price stability is to be pursued over a medium-term horizon (ECB, 1999). This is a clear acknowledgement that attempting to hit an inflation target on a period-by-period basis would involve significant output losses and instrument instability. Of course, the ECB's (as well as the US Fed's) policy strategy does not involve an explicit inflation-forecast approach à la Svensson (1997a, b), unlike the approach followed by the Bank of England. However, as we shall see below, forward-looking interest rate rules, based on inflation forecasts, appear to adequately characterise the monetary policy behaviour in a range of countries.

Before turning to these forward-looking rules, we first briefly examine earlier attempts to model interest rate rules. Much attention has been given to so-called Taylor rules (see Taylor, 1993). Taylor rules link the policy instrument (short-term interest rate) to the current values of actual inflation and the output gap. The general form of these rules is (ignoring the constant term): ${ }^{9}$

$$
R_{t}=\chi_{\pi} \pi_{t}+\chi_{y}\left(y-y^{*}\right)_{t},
$$

where the optimal relative magnitude to be assigned to the $\chi$ parameters could be devised in order to minimise output and inflation variability around their steadystate values. Taylor (1993) suggests adopting $\chi_{\pi}=1.5, \chi_{y}=0.5$.

Rules like (1) have a considerable practical appeal, given their relative simplicity and clarity. Gerlach and Schnabel (2000), for example, find that a simple Taylor rule expressed in terms of aggregate average output gaps and inflation provides a 
good explanation of average interest rates movements in EMU countries between 1990-98. Peersman and Smets (1999) carry out a similar experiment, by investigating the stabilisation properties of the Taylor rule in a model of the Euro area, using aggregate data. In addition, an optimised version of the general rule in (1) is robust to small changes in the model parameters, in line with the findings of Rudebusch and Svensson (1999) for the US.

However, these properties hinge on the assumption that observed real and nominal magnitudes characterise economies that are in a steady state. This seems unlikely given some of the regime shifts that have characterised the OECD economies in the last two decades. In addition, McCallum (1999) and McCallum and Nelson (1998) forcefully argue that the optimal behaviour of private agents in recent macroeconomic intertemporal models (see Bernanke, Gertler and Gilchrist, 1999; Rotemberg and Woodford, 1999) requires the inclusion of a forwardlooking term for inflation (and possibly the output gap) in an optimal interest rate rule. This would call for interest rate rules generally closer to the rule we consider in equation (3) below.

Turning next to forward-looking policy rules, Clarida and Gertler (1997) represents the first explicit attempt to estimate such an interest-rate rule, departing from conventional Taylor rules or other types of backward-looking rule expressed in terms of lagged or current inflation. ${ }^{10}$ They estimated a reaction function for the Bundesbank's short-term interest rate instrument, finding no apparent role for the growth of M3 in a simple rule expressed in terms of output and inflation objectives. Their overall conclusion is that Bundesbank's and Fed policies can be characterised as following a reasonably similar pattern, and that monetary targets do not play an important role in monetary policy setting.

Clarida, Gali and Gertler (1998) (CGG, henceforth) extended this approach, by estimating interest rate reaction functions for the G7 countries between 19801997, using new measures of expected inflation and potential output compared to those used in Clarida and Gertler (1997). Their model posits that monetary authorities' preferences are known with complete certainty by the private sector. Moreover, the authorities have full information about the state of the economy. One problem with the CGG approach is that they use their estimates to derive conclusions about the monetary authorities' underlying inflation target. As shown in Appendix A, one cannot straightforwardly identify the policy preferences parameters from an estimated forward-looking policy rule.

Muscatelli, Tirelli and Trecroci (1999) (MTT, henceforth) generalise the CGG approach by allowing for a more general form of policy rule, and using alternative measures of the output gap and forecast inflation. Following Batini and Haldane (1999) and Svensson (1997b), the typical form of an inflation-forecast interest rate rule is

$$
r_{t}=\theta r_{t}^{*}+\varphi r_{t-k}+\gamma E_{t} \pi_{t+j}+\lambda\left(y_{t}-y_{t}^{*}\right),
$$

where $r_{t}$ is the short-term ex-ante real interest rate, $r_{t}^{*}$ represents its long-run equilibrium value, $E_{t} \pi_{t+j}$ indicates the $j$-period ahead inflation rate expected in time $t$, and the last RHS term again represents the output gap, expressed as 
deviations of actual output from its potential level. In Appendix A we show how an interest rule akin to (2) can be explicitly derived from a standard optimising framework.

Optimal inflation stabilisation involves adjusting the nominal interest rate so that the implied change in the real interest rate fully offsets the observed variation in expected inflation. A stable outcome is attainable if the costs associated with interest rate changes are not too big (see Appendix A). The presence of lagged terms of the real interest rate accounts for the observed interest-rate smoothing behaviour of many central banks (see Goodhart, 1996). It also allows for the possibility that interest rate changes might be postponed to avoid undesired disruption of the current level of economic activity (Batini and Haldane, 1999). The latter argument also implies that the presence of an output gap term in [2] might not be strictly necessary to account for authorities' concern for output stabilisation. By tuning the degree of interest-rate smoothing and the lead in the inflation forecast, the bank can be seen to trade off output volatility for inflation volatility.

Eq. (2) can be trivially re-parameterised in terms of the nominal short-term interest rate. In addition, by including a longer lead for expected inflation and a longer lag for the interest-rate smoothing term, one obtains a reaction function defined in terms of the policy instrument:

$$
R_{t}=\mu_{0}+\sum_{i=1}^{k} \mu_{i} R_{t-i}+\vartheta E_{t} \pi_{i+j}+\lambda\left(y_{t}-y_{t}^{*}\right)
$$

The specification in (3), which is adopted by MTT, allows empirical testing of many issues in the literature on optimal forecast-based policy rules. The estimated weights which the central bank places on the expected inflation, and the lead-length of such term $(\vartheta, j)$, reveal the degree of aggression with which the bank reacts to changes in the inflation forecast, and the extent of 'forward-lookingness' in central bank's behaviour. The parameters $(j, k, \mu)$ in turn capture the overall degree of inertia in interest rate policy. Finally, a significant value for $\lambda$ would reflect the bank's concern over output, over and beyond the output stabilisation which would arise from interest-rate smoothing terms and the lead/lag parameters. ${ }^{11}$

MTT find that the reaction lead to expected inflation is, in most cases, four quarters, but in other instances this turned out to be between two and four quarters. This matches Batini and Haldane's (1999) dynamic simulations on a calibrated model of a small open economy, which show that the optimum lead length should lie between three and six quarters. Amato and Laubach's (1999) study for the US economy find the optimum lead to be between five and eight quarters, but their baseline interest rate rule involves no output stabilisation at the outset. Rudebusch and Svensson (1999) examine the performance of alternative policy rules on a small simulated model of the US economy, finding a broad support for forecast-based rules like (3).

In general, MTT and CGG also detect a substantial amount of policy inertia in all the countries examined, as lags of the dependent variable are always 
significant. This also agrees with Batini and Haldane's findings and with Woodford (1999), who argues that in the presence of a zero lower bound on nominal interest rates and positive costs of inflation, a central bank's commitment to sluggish interest-rate changes enhances social welfare.

However, estimating monetary policy reaction functions over long samples requires considerable caution. Setting interest rates usually involves a complex decision-making process, where a policy committee or council sets interest rates based on a host of different macroeconomic indicators and models (see Bank of England, 1999; Vickers, 1999). Where interest rates are set by committee each member of the decision-making body might rely on a different sub-set of indicators and might have a preferred 'model' of the transmission mechanism. Estimated interest rate reaction functions clearly cannot, and do not set out to, model every aspect of this complex decision-making process. Instead, they focus on simple policy rules where interest rates respond to expected inflation and the output gap (and display some short-term inertia). If the estimated reaction functions are found to be stable, this can be seen as an indication that the actual information set used by the policy authorities displays a stable relationship with the final policy objectives (output and inflation) in the estimated rule and that the policy authorities' preferences did not change over the estimation sample. On the other hand, if one detects instability in a reaction function such as (3), this would indicate either a shift in policy preferences or a shift in the relationship between the final objectives of policy and the wider information set (including the many indicators) used by the policy committee. ${ }^{12}$

Therefore stability analysis on estimated reaction functions can be used to gain some insights on the effects of institutional changes (like the introduction of inflation targets and/or the granting of central bank independence) on the conduct of interest rate policies.

However, the estimation of interest rate rules like (3) or (1) also involves additional problems. A key problem is that of modelling expected inflation and the output gap, which are the two explanatory variables in the model. Various forecasting and filtering procedures can be used. However, particularly if one wishes to fit a model over a long time horizon, one has to take into account underlying structural change. The growth rate in potential output has varied in the OECD economies in the last 30 years, and inflation expectations will also have been subject to regime shifts coupled with gradual learning. What one needs to capture in these models is the way in which the authorities perceive the evolution of the trend in potential output, and how inflation expectations are updated. Hence, some allowance has to be made for gradual learning in the model. For instance, one should assume that the central bank and the private sector formulate their expectations about future inflation and output using only information available up to the time period in which such expectations are formed. The resulting model would be one that allows for a learning process whereby the central bank gains new information.

The key issues in evaluating estimated forward-looking policy rules are therefore the following: a) the methods used to identify measures of expected 
inflation and the output gap; b) the estimation techniques used to estimate the reaction function and to test them for structural breaks; and c) the sample covered by the estimates. We can examine these issues in the context of the two studies already cited: Clarida, Gali and Gertler (1998) and Muscatelli, Tirelli and Trecroci (1999).

Both CGG and MTT estimate equations similar to (3). CGG employ a quadratic trend to obtain measures of potential output and hence deviations of actual output from this trend. In order to obtain a measure of inflation expectations, CGG use the errors-in-variables approach to modelling rational expectations whereby future actual values are used as regressors instead of the expected values, and instrumental variable estimation is used to take account of the presence of forecast errors. In contrast, MTT employ a Kalman filter technique applied to Structural Time Series models (Harvey, 1989; Kim and Nelson, 1999) to generate the regressors (expected inflation, output gap) needed in the subsequent estimation of the reaction function in (3). Essentially, MTT assume that the private sector is imperfectly informed about the central bank preferences, and that the central bank is imperfectly informed about the permanent and cyclical components of output growth (see Orphanides, 1999). They proxy this learning process via a Kalman Filter estimation technique. In turn, MTT ${ }^{13}$ estimate reaction functions of the form in equation (3) for the G-3 and a group of four inflation-targeting regimes, using simple recursive OLS and testing for the stability of estimated parameters and functions. CGG tend to present only full-sample estimates and do not conduct any formal stability analysis, although they show that the nature of monetary policy rules changed sharply around 1980 .

For reasons of space, here we limit our comparison to the results for the US and Germany. The essential difference between MTT and CGG is that the latter uses full-sample information in modelling the output gap and inflation expectations, whilst the former assumes that a gradual learning process is taking place.

CGG's preferred model for the USA is as follows:

$$
R_{t}=\left(1-\rho_{1}-\rho_{2}\right)\left[\alpha+\beta \pi_{t+n}+\gamma\left(y_{t}-y_{t}^{*}\right)\right]+\rho_{1} R_{t-1}+\rho_{2} R_{t-2}+\varepsilon_{t},
$$

Parameter estimates for (4) are reported in the bottom panel of Table 1. Overall, CGG argue that the early 1980s mark a watershed in the conduct of monetary policy. Since then the Fed appears to have turned invariably more aggressive in the use of interest rate changes in response to changes in expected inflation. CGG suggest that since 1982 US monetary policy appears to have converged de facto to a standard inflation targeting regime, in which output stabilisation concerns also matter. This view of the Fed's implicit behaviour is not supported by a later study by Favero and Rovelli (1999), who claim that a significant output effect in an estimated reaction function might simply reveal that the central bank employs the current output gap as an indicator for future expected inflation. However, should this be the case, the output gap should be collinear with the adopted measure of expected inflation, or it should be able to improve inflation forecasts. However, MTT were unable to find a significant 
Table 1. Estimated Reaction Functions: Clarida, Gali and Gertler (1998).

\begin{tabular}{lccccc}
\hline \hline Bundesbank. Sample: $1979 \mathrm{M} 3-1993 \mathrm{M} 12$. & & & & \\
& $\beta$ & $\gamma$ & $\rho$ & & $\zeta$ \\
\hline Baseline & 1.31 & 0.25 & 0.91 & 3.14 & - \\
& $(0.09)$ & $(0.04)$ & $(0.01)$ & $(0.28)$ & \\
Adding: & & & & & \\
Lagged Inflation & 1.10 & 0.28 & 0.91 & 3.26 & 0.12 \\
& $(0.20)$ & $(0.04)$ & $(0.01)$ & $(0.71)$ & $(0.14)$ \\
Money Supply & 1.29 & 0.28 & 0.91 & 3.12 & 0.7 \\
& $(0.08)$ & $(0.03)$ & $(0.01)$ & $(0.29)$ & $(0.07)$ \\
FFR & 1.23 & 0.25 & 0.91 & 2.71 & 0.007 \\
& $(0.06)$ & $(0.04)$ & $(0.01)$ & $(0.84)$ & $(0.02)$ \\
Real Exchange Rate & 1.37 & 0.35 & 0.91 & -0.93 & 0.05 \\
& $(0.09)$ & $(0.04)$ & $(0.01)$ & $(0.82)$ & $(0.01)$
\end{tabular}

Fed. Sample: 1979M10-1994M12.

\begin{tabular}{lccccc} 
& $\beta$ & $\gamma$ & $\rho_{1}+\rho_{2}$ & $\alpha$ & $\zeta$ \\
\hline Baseline & 1.79 & 0.07 & 0.92 & 0.26 & - \\
Post 1982M10 & $(0.18)$ & $(0.06)$ & $(0.03)$ & $(0.85)$ & \\
& 1.83 & 0.56 & 0.97 & -0.10 & -
\end{tabular}

Adding:

$\begin{array}{lccccc}\text { Lagged Inflation } & 2.20 & 0.14 & 0.94 & -0.45 & -0.25 \\ & (0.75) & (0.10) & (0.05) & (1.65) & (0.40) \\ \text { Post 1982M10 } & 1.99 & 0.75 & 0.97 & 2.09 & -0.78 \\ & (0.67) & (0.25) & (0.05) & (2.33) & (0.54) \\ \text { Money Growth } & 1.05 & 0.44 & 0.90 & 0.80 & 0.53 \\ & (0.14) & (0.07) & (0.05) & (0.51) & (0.08) \\ \text { Post 1982M10 } & 1.26 & 0.52 & 0.96 & 1.03 & 0.21 \\ & (0.24) & (0.06) & (0.04) & (0.25) & (0.04)\end{array}$

Notes: see main text for the specification adopted. In both cases estimates are obtained by GMM with correction for MA(12) autocorrelation. Standard errors in parentheses. The error term is defined as

$$
\varepsilon_{t} \equiv-(1-\rho)\left\{\beta\left(\pi_{t+12}-E\left[\pi_{t+12} \mid \Omega_{t}\right]\right)+\gamma\left[\left(y_{t}-y_{t}^{*}\right)-\gamma E\left[\left(y_{t}-y_{t}^{*}\right) \mid \Omega_{t}\right]\right]\right\}+v_{t}
$$

with $\alpha=R^{l r}-\beta \pi^{*}$ and $R_{t}=$ policy instrument; $\Omega_{t}=$ information set at time $t ; R^{l r}=$ long-run equilibrium nominal interest rate; $\pi^{*}=$ inflation target.

contemporaneous correlation between their measures of expected inflation and the output gap. In addition, the contemporaneous correlation with inflation forecast errors appears very small and often has the wrong sign. ${ }^{14}$

For the German Bundesbank, CGG estimate

$$
R_{t}=(1-\rho) \alpha+(1-\rho) \beta \pi_{t+n}+(1-\rho) \gamma\left(y_{t}-y_{t}^{*}\right)+\rho_{1} R_{t-1}+\varepsilon_{t},
$$

The estimation results are reported in the top panel of Table 1. The large coefficient associated with the inflation term suggests that the Bundesbank raised interest rates by a substantial amount in response to inflationary pressures. In 
addition to the output gap and expected inflation, CGG test for the inclusion of additional intermediate objectives such as monetary growth (parameter $\zeta$ ). Interestingly, while the coefficient on money growth does not appear to be significant, the coefficient on the output gap does. This confirms that the Bundesbank's monetary targets were not the Bank's primary objective and that discretionary undershoots and overshoots of the target bands were allowed where this did not impair the achievement of the inflationary objective.

This result is broadly confirmed by MTT's findings, who estimate equation (3). The long-run solution of the estimated equation is reported in Table 2. ${ }^{15}$ Recursive least squares estimation detects policy shifts. As noted above, parameter shifts can be interpreted either as shifts in the relationship between the central bank's wider information set and the policy objectives included in the reaction function, or as shifts in policy preferences. Clearly, the interpretation of parameter instability in the reaction function requires considerable care, but in general major and permanent shifts in estimated reaction function coefficients can be attributed to shifts in policy preferences.

Interestingly, the full-sample results in Table 2 for Germany show that interest rates react to both inflation expectations (with a point estimate greater than 1) and the output gap. Variable addition tests show that neither money growth nor the exchange rate (measured as the DM-US\$ rate) seems to exert an independent significant effect on German interest rates. This confirms analogous results in Clarida and Gertler (1997), CGG, and Bernanke and Mihov (1997).

The estimated reaction function for Germany displays no major shifts, with the estimated coefficients constant across sub-samples. MTT also found that a fourquarter lead for expected inflation works best for both the full sample and the post-1980 sample. Figure 2 shows 1-step and N-step down Chow tests for the post-1980 regression, as well as the estimated long-run coefficients and (asymptotic) standard errors for the expected inflation and output gap. This confirms the stability of the Bundesbank's policy rule, but shows that the size of the estimated response to the output gap fell after the unification shock in 1991. The main finding, in line with CGG, is that monetary policy in Germany reacted systematically to cyclical conditions, although the Bundesbank's declared monetary strategy was expressed in terms of monetary targets. Additional information emerges from MTT's recursive estimates. From 1980 onwards (and post-unification) the overall policy thrust gradually turned more conservative. Whilst 1980 does mark a watershed in monetary policy in Germany, our recursive estimates indicate a much more gradual policy change.

The USA reaction function estimated by MTT over the 1971-1996 period (see Table 2 and Figure 2) is characterised by a coefficient on inflation which is not significantly larger than one and by a significant coefficient on the output gap. Estimates over the post-1980 sample confirm that some important changes seem to have taken place. US policy does seem to have been less constant over time than Germany's, and the response to output was perverse until 1992. Interest rates seem to react to inflation expectations on a shorter horizon (a 2-quarter horizon is found to work best post-1985) and with a larger coefficient when the reaction 
Table 2. Estimated Reaction Functions: Muscatelli, Tirelli, and Trecroci (1999).

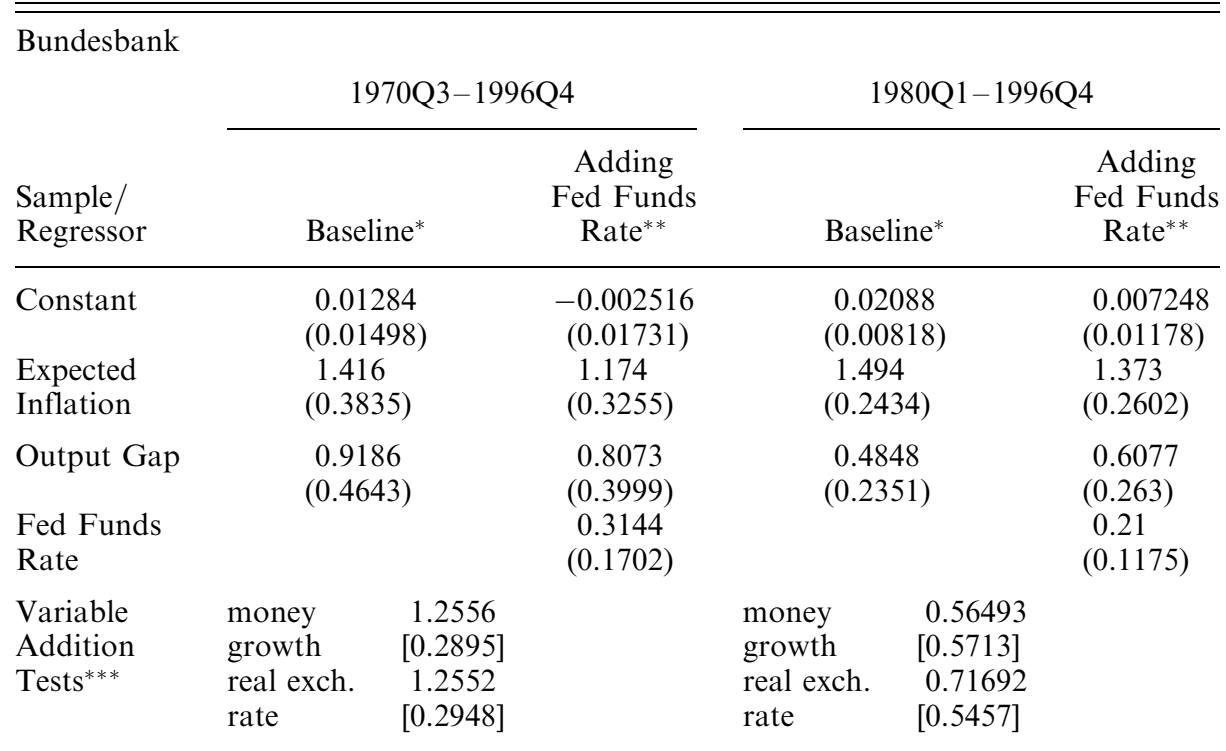

* Derived from a RLS regression of the interest rate on a constant, 4-quarter ahead expected inflation, output gap and one lag of the dependent variable.

** As for the note above, but now with two lags of the Fed Funds Rate on the RHS.

${ }^{* * *}$ Tests for the addition of other regressors. Zero restrictions on lagged money growth and changes in the current and lagged exchange rate vis-à-vis the US\$ were tested by a F-version of the Wald test. Pvalues in brackets.

Fed

Sample/

\begin{tabular}{|c|c|c|c|c|c|c|}
\hline Regressor & \multicolumn{2}{|c|}{ 1971Q4-1996Q3* } & \multicolumn{2}{|c|}{ 1980Q1-1996Q3* } & \multicolumn{2}{|c|}{ 1985Q1-1996Q3** } \\
\hline Constant & \multicolumn{2}{|c|}{$\begin{array}{c}0.02213 \\
(0.02348)\end{array}$} & \multicolumn{2}{|c|}{$\begin{array}{c}0.006149 \\
(0.02366)\end{array}$} & \multicolumn{2}{|c|}{$\begin{array}{c}0.02422 \\
(0.007616)\end{array}$} \\
\hline $\begin{array}{l}\text { Expected } \\
\text { Inflation }\end{array}$ & \multicolumn{2}{|c|}{$\begin{array}{l}1.18 \\
(0.4148)\end{array}$} & \multicolumn{2}{|c|}{$\begin{array}{l}1.81 \\
(0.5315)\end{array}$} & \multicolumn{2}{|c|}{$\begin{array}{c}1.079 \\
(0.2148)\end{array}$} \\
\hline Output Gap & \multicolumn{2}{|c|}{$\begin{array}{l}1.572 \\
(0.7553)\end{array}$} & \multicolumn{2}{|c|}{$\begin{array}{c}0.9438 \\
(0.6183)\end{array}$} & \multicolumn{2}{|c|}{$\begin{array}{c}0.9266 \\
(0.1387)\end{array}$} \\
\hline Variable & money & 0.02210 & money & 0.04188 & money & 0.05796 \\
\hline Addition & growth & {$[0.9781]$} & growth & [0.9590] & growth & [0.9438] \\
\hline Tests*** & $\begin{array}{l}\text { real exch } \\
\text { rate }\end{array}$ & $\begin{array}{c}1.1505 \\
{[0.3211]}\end{array}$ & $\begin{array}{l}\text { real exch. } \\
\text { rate }\end{array}$ & $\begin{array}{l}0.36603 \\
{[0.6950]}\end{array}$ & $\begin{array}{l}\text { real exch. } \\
\text { rate }\end{array}$ & $\begin{array}{l}0.11224 \\
{[0.8941]}\end{array}$ \\
\hline
\end{tabular}

* Derived from a RLS regression of the interest rate on a constant, 4-quarter ahead expected inflation, output gap and two lags of the dependent variable.

${ }^{* *}$ Derived from a RLS regression of the interest rate on a constant, 2-quarter ahead expected inflation, output gap and one lag of the dependent variable.

${ }^{* * *}$ Tests for the addition of other regressors. Zero restrictions on lagged money growth and changes in a lagged trade-weighted index of effective exchange rate were tested by a F-version of the Wald test on the baseline model augmented of each new variable. P-values in brackets.

Note: see main text for the specification adopted. Asymptotic standard errors are in parentheses.

(C) Blackwell Publishers Ltd. 2000 

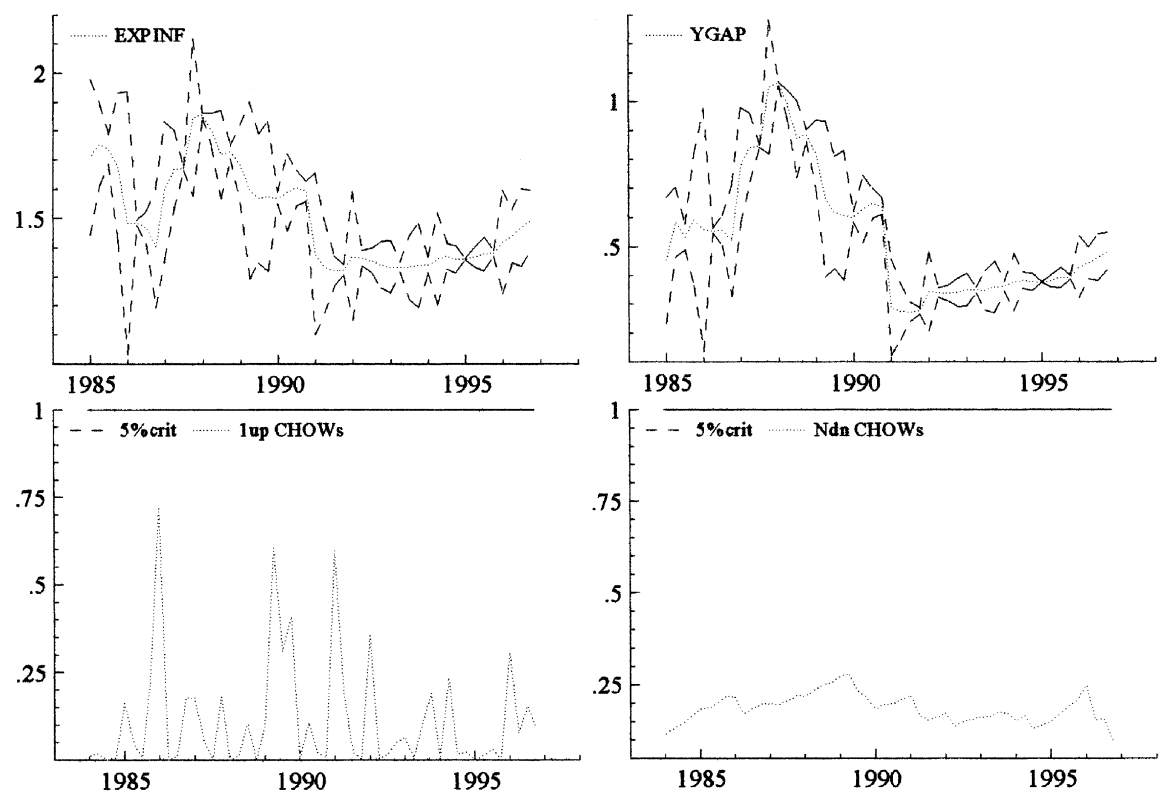

\section{Germany, 1980(1)-1996(4).}
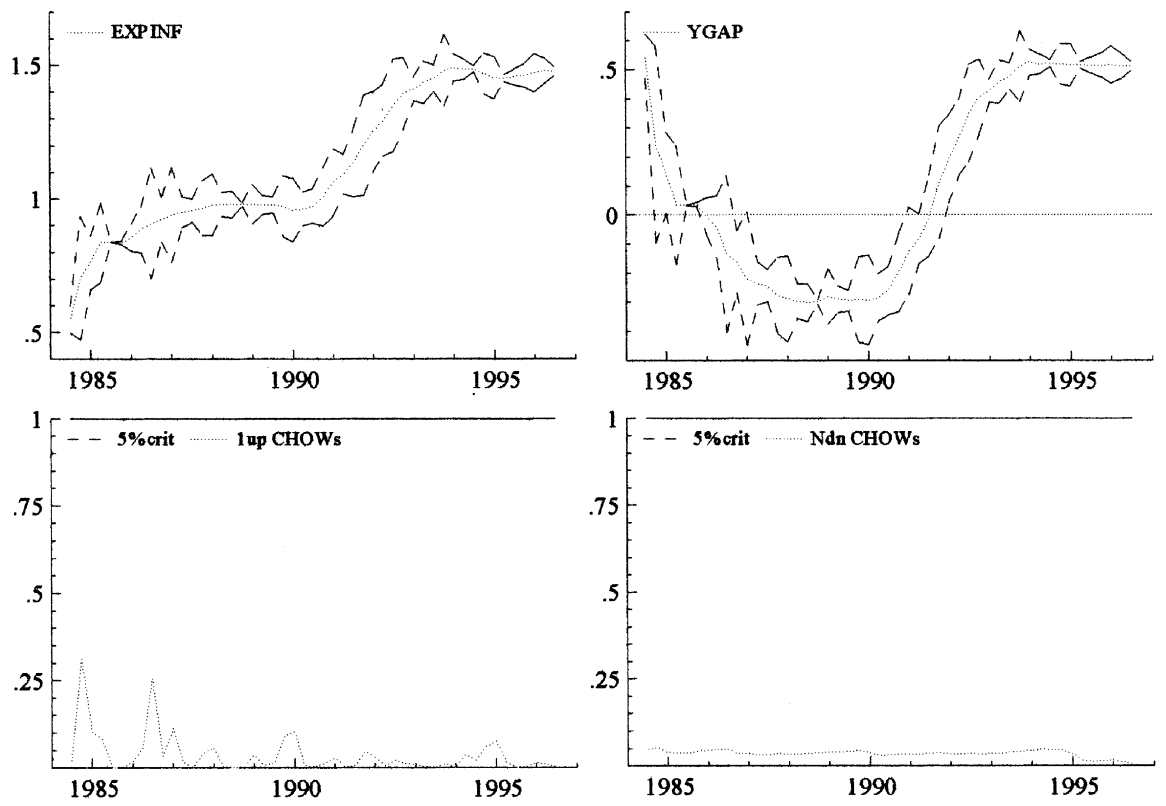

USA, 1980(1)-1996(3).

Figure 2. Recursive coefficients and standard error bands; 1-step, N-step up Chow tests $(5 \%)$.

(C) Blackwell Publishers Ltd. 2000 
function is re-estimated over the latter part of the sample. These results contrast with the conclusions of CGG, as CGG find an estimated coefficient on inflation that is much greater than one.

The picture changes completely if we focus on the post-1985 sample. The parameters tend to remain stable, and the coefficient on expected inflation has a point estimate greater than unity (although it is not significantly larger than 1). The recursive graphs also confirm that in the 1990s the Fed was adjusting real rates to follow the output cycle much more closely.

Overall, the Fed looks very different from the Bundesbank until the 1990s. On this point MTT's results differ sharply from those of CGG. CGG's results suggest that, having successfully restrained inflation expectations in 1979-82, the Fed exploited her reputation to implement countercyclical policies. But MTT's estimated Fed's policy coefficients (particularly the output gap coefficient) suggest that a stable and correctly-signed reaction function only operated from the early 1990s. These findings also broadly illustrate a substantive difference between the Fed's and Bundesbank's monetary strategies.

The Bundesbank appears to have responded more forcefully to movements in expected inflation than the Fed judging from the inflation expectation coefficient. Some authors have suggested that this result is open to other interpretations. Mishkin (1999) and Mishkin and Posen (1997) label the Fed policy as 'just do it', or pre-emptive policy without a nominal anchor. Their argument is that monetary policy must act well in advance of a surge in inflation expectations since the full impact of monetary policy on inflation has long lags. The main disadvantage of such a policy obviously lies in the difficulty of establishing a clear policy pattern with all the risks that this implies at times when the economy is being hit by major exogenous shocks. MTT's results suggest that such pragmatic and forwardlooking policy should not be interpreted as if the Fed systematically reacted to longer-term expectations, as in the Bundesbank's case. In fact MTT found that shorter leads on the expected inflation variable ( 2 instead of 4 quarters) seemed to work better for the US post-1985 sample. Overall, MTT's results suggest that the Fed might have been learning slowly how to deal with the new non-inflationary environment of the 1990s, and this led to a variable response.

Interestingly, MTT's recursive graphs in Figure 2 show that the size of the reaction function coefficients do tend to converge, eventually, towards the optimal values of a standard Taylor rule. The most likely interpretation ${ }^{16}$ for this is that the period from the mid-1990s onwards represents something akin to a 'steadystate' for monetary policy. Interest rate behaviour as generated by forwardlooking policy rules as in MTT and backward-looking specifications like the Taylor rule would appear as observationally equivalent in a model where inflation does not display major predictable shifts. The 1990s have been a stable macroeconomic environment and, in such an environment, both rules work reasonably well. Hence, it is not surprising to find this convergence.

Finally, we should note that MTT do not find a straightforward link between institutional change and policy rule shifts. In addition to the results which have been reported here, they present similar estimates for the other G3 economy, 
Japan, and some economies which switched to explicit inflation targeting in the late 1980s and early 1990s (the UK, Canada, Sweden, and New Zealand). Whilst MTT find that in the case of some inflation targeters (the UK post-1992, Canada post-1990) the reaction function shifted, ${ }^{17}$ in other cases there was little evidence of parameter instability in the proximity of periods of institutional change. In contrast, in the US and Japan policy shifts took place which seem unconnected to institutional change.

\section{VAR models and monetary policy rules}

Having considered the estimation of single-equation monetary policy rules, we now survey how policy rules are identified and estimated in the context of VAR models. Given space constraints, we cannot provide a full and comprehensive survey of the use of VARs for monetary policy analysis. Useful surveys are already available on both VAR estimation (see e.g. Canova, 1995) and applications of VARs to the monetary policy context (see Christiano et al., 1998). We shall limit our attention mainly to the problem of identifying monetary policy rules in VARs.

\subsection{Introduction: the use of $V A R s$}

The use of VAR models to analyse monetary policy has grown exponentially since Sims' (1980). Essentially VAR analyses of monetary policy involve:

(i) estimating a reduced-form vector autoregressive model which include several key policy variables, final objectives, and intermediate objectives of monetary policy. Typically all the variables included are treated as endogenous, to avoid imposing the spurious or false identifying restrictions which Sims (1980) warned against.

(ii) applying some restrictions to the VAR in order to just-identify the model, and examine the effects of the primitive (or structural) shocks of the model through impulse response analysis. These impulse responses can then be given an economic interpretation.

Formally, the reduced form VAR can be written as:

$$
X_{t}=c+A(L) X_{t-j}+\varepsilon_{t}
$$

where $X_{t}$ is a $(n \times 1)$ vector of endogenous variables, $A(L)$ is a matrix of lag polynomials of order $p$ (where $p$ is the maximum lag in the estimated VAR), and $\varepsilon_{t}$ is a $(n \times 1)$ vector of disturbances for which:

$$
\begin{aligned}
E\left\{\varepsilon_{t}\right\} & =0 \\
E\left\{\varepsilon_{t} \varepsilon_{t}^{\prime}\right\} & =\Sigma \\
E\left\{\varepsilon_{t} \varepsilon_{s}^{\prime}\right\} & =0, \forall t \neq s
\end{aligned}
$$


However, in practice we are not interested in the response of the variables to the reduced-form VAR innovations, $\varepsilon_{t}$, but in a structural interpretation of the dynamic relationship between the jointly endogenous variables. Consider the following general dynamic structural model between the variables $X_{t}$ :

$$
B_{0} X_{t}=k+B_{1} X_{t-1}+B_{2} X_{t-2}+\cdots+B_{p} X_{t-p}+u_{t}
$$

where the structural disturbances $u$ are white-noise. ${ }^{18}$ By pre-multiplying each side of the equation in (8) by $B_{0}^{-1}$, we arrive at the reduced form VAR in (6):

$$
X_{t}=c+A_{1} X_{t-1}+A_{2} X_{t-2}+\cdots+A_{p} X_{t-p}+\varepsilon_{t}
$$

where $c=B_{0}^{-1} k, A_{i}=B_{0}^{-1} B_{i}, \varepsilon_{t}=B_{0}^{-1} u_{t}$

Hence the reduced-form VAR can be seen as a reduced-form representation of the dynamic structural system in (8). Given the economic model underlying the $u$ can be given a structural economic interpretation (e.g. aggregate supply, money demand shocks). Typically the economist will be interested in how the variables respond to these structural shocks over time. This is the basis of impulse response analysis, which illustrates the dynamic response of the $X_{t}$ to shocks in the structural innovations.

However, whilst the reduced form specification is unambiguous (past values of all the jointly endogenous variables enter all the equations of the system), the structural specification is not. Having estimated the reduced form VAR, the problem is one of imposing the appropriate identification restrictions, which allow one to identify the structural disturbances in the model. This is the classic textbook problem of identification.

The difficulty, as illustrated by Sims (1980), is that economic theory seldom provides us with a clear indication of the pattern of dynamic interactions between variables. The danger is that one ends up imposing false or spurious identifying restrictions on the model. VAR modellers have used a variety of different types of identifying restrictions to confront the identification problem. One common approach is to impose a recursive structure to the model, sometime known as a Choleski decomposition. The usual recursive ordering imposed on models of the monetary transmission mechanism assumes that monetary policy actions affect only target variables such as output and prices with a lag. Thus, in Christiano et al. (1996) and Bernanke and Mihov's (1998) analysis of US monetary policy a typical causal ordering considered is: real output; consumer prices; commodity prices; non-borrowed bank reserves; the federal funds rate; total bank reserves.

The problem with imposing a fixed identification structure to the model when a large number of variables are used is that the appropriate causal ordering might vary over the sample period. For instance, we know that the US Fed in the 197982 period targeted non-borrowed reserves, as opposed to the federal funds rate. This would affect the appropriate causal ordering of these two variables in the structural form ${ }^{19}$ of the VAR. Another problem with a simple recursive structure is that, whilst it might work well with monthly data, with lower frequency data such as quarterly data a within-period response of non-policy variables to shocks to the instrument variable is likely to occur. Indeed a more general criticism of 
recursive structures is that they are extremely restrictive, and may only hold for specific sets of non-policy and policy variables.

Some authors (cf. Christiano et al., 1998 and Sims, 1996) argue that in general the results which emerge on the nature of the monetary policy transmission mechanism are robust to the chosen identification restrictions. Faust (1998) points out $^{20}$ that any statement about robustness should be backed up by formal empirical evidence. He suggests a way of examining the robustness of responses to different identification assumptions, also allowing for more general restrictions on the short-run impulse responses than the usual contemporaneous restrictions implied by simple recursive structures. He demonstrates that different identification structures can have a significant impact on the results of VAR analyses of monetary policy.

Finally, most analyses of monetary policy VARs tend to focus on short-run restrictions, eschewing the type of long-run restrictions considered by Blanchard and Quah (1989) in their VAR analysis of aggregate demand and supply shocks. The reason is principally that economic theory suggests very few long-run restrictions that could be imposed with total confidence. Furthermore, given the nature of the time series involved (e.g. the degree of integration) long-run restrictions may impose binding constraints on the data.

\subsection{Identifying monetary policy rules in VARs}

The implicit policy rules that emerge from VARs once the identification restrictions have been imposed are rarely interpretable in practice, and this has been a source of considerable criticism of monetary policy VARs. For instance, Rudebusch (1998) reports the following interest rate (federal funds rate) equation from a quarterly ${ }^{21}$ VAR for the sample period 1960:1-1995:1 (we only report estimated coefficients significant at the $10 \%$ level):

$$
\begin{aligned}
f f r_{t}= & 0.25 y_{t}+0.817 \text { pcom }_{t}-0.979 p c_{t-3} \\
& +0.438 p c_{t-4}+1.075 f f r_{t-1}-0.33 f f r_{t-2}+0.363 f f r_{t-3}
\end{aligned}
$$

where (in addition to those variables reported) four lags are included of real output $(y)$, consumer prices $(p c)$, commodity prices $(p c o m)$, the funds rate $(f f r)$, non-borrowed reserves ( $n b r)$ and total reserves ( $t r)$, and the recursive identification structure described in Section 4.1 is used. Very few of the estimated coefficients are significant, as even a 6-variable VAR is typically overparameterised, and little sense can be made of those coefficients which are significant.

Other authors have stressed difficulties with such estimated 'policy rules' in VARs. First, as noted by Christiano et al. (1998), if the actual policy rule is forwardlooking, the estimated coefficients of such VAR-estimated 'policy rules' will be difficult to interpret. In this case, a single-equation 'forward-looking' policy reaction function as in Clarida et al. (1998), Muscatelli et al. (1999) and Favero and Rovelli (1999) might yield more interpretable results. Second, as noted by Rudebusch (1998), Bagliano and Favero (1998) and, as implied by the Bernanke-Mihov (1998) 
study, estimated policy rules which span different operating regimes are likely to yield very different results. Third, Rudebusch (1998) stresses the fact that data revisions are likely to affect estimates of policy rules. The econometrician does not have at his/her disposal the set of preliminary data on the basis of which policymakers actually decided on interest rates. Instead we use data which has been subjected to several revisions. ${ }^{22}$ Fourth, as noted above, the advantage of singleequation policy rules is that they enable one to focus solely on the target variables of interest (e.g. the output gap and expected inflation). Insofar as policymakers actually base their interest rate policies on a wider information set, this will be reflected in shifts in the policy rule which is conditioned on the more limited set of target variables. These shifts in the forward-looking interest rate policy rule can then be interpreted either in the light of changes in operating procedures or in the light of shifts in policy preferences. In contrast unrestricted VARs typically include all the other non-policy variables which characterise the transmission mechanism and it becomes difficult to interpret the 'VAR policy rules' in the light of the final policy objectives (mainly output and inflation stabilisation). As noted below, this has pushed some researchers to argue for the use of VARs of smaller dimensions when one is seeking to identify policy rules.

Finally, one should note that, if one takes the 6-variable VARs discussed previously, or even VARs of larger dimensions (see Bernanke and Mihov, 1998, Leeper et al., 1996, Faust, 1998), the structural innovations in the interest rate equation occasionally bear little relation to 'policy shocks'. This is discussed fully in Rudebusch (1998) and Faust (1998). There seems little doubt that these innovations in the interest rate equation are probably related to sudden shifts in the demand for bank reserves where the monetary authorities do not seek to control short-term market rates tightly. Indeed, Rudebusch (1998) shows that there is little relation between these VAR 'policy shocks' and the expectations of monetary shocks that emerge from data on federal funds market futures. This suggests that, if the federal funds rate is not really tightly controlled by the authorities, the usual recursive identification assumption in VAR models is flawed for some sample observations. Again, this suggests that one should not rely on a single set of identifying restrictions in a large-dimension VAR, but adopt robustness checks as suggested by Faust (1998).

\subsection{Small-dimension VARs and policy rule identification}

Given the above discussion we would argue that small-dimension VARs provide some advantages in identifying policy rules compared to the typical 6, 7 or even 13-variable VARs normally employed in studies of the transmission mechanism. Clearly there is no way that a VAR model, no matter how large its dimensions, could capture the full information set on which the monetary policy authority (or a member of its policy-making committee) bases its decisions. As noted in Section 3, in practice the decisions of the policy authority/committee will be a (deterministic?) function of a large information set. By focusing on a smaller subset of this information set, but one that is still large relative to the available 
observations, the econometrician is trading off some overparameterisation for some oversimplification. But even 6 or 7 -variable VARs are still overparameterised in their unrestricted form and this suggests that the choice of the appropriate dimension of the VAR should depend on the question that the applied econometrician is trying to answer. Thus, if the purpose is to identify how interest rate policy has reacted to final policy objectives, it might be better to ignore other indicators and intermediate objectives, and estimate a VAR of small dimensions. On the other hand, if the purpose is to understand the relationships between a large set of macroeconomic indicators in the transmission mechanism, all the variables of interest should be included.

Rudebusch and Svensson (1999) estimate a trivariate VAR for the US economy, including the output gap, inflation and the federal funds rate. They demonstrate that even in such a small VAR it is difficult to interpret the interest policy reaction to inflation and output shocks as a 'policy rule': for instance the interest rate response to an inflationary shock is less than one, which suggests that real interest rates do not rise in response to inflationary shocks. However, as noted in Muscatelli and Trecroci (2000), in part this is a problem which arises from using a long sample, starting from the early 1960s, which includes very different policy regimes.

Muscatelli and Trecroci (2000) estimate a similar trivariate VAR for the UK and US, with some important modifications. First, allowance is made for changes in the transmission mechanism if economic agents are forward-looking. Changes in the policy regime will bring about shifts in the responsiveness of output and inflation to interest rates if both aggregate demand and supply contain forward-looking expectations. The role of forward-looking expectations and hence the Lucas critique has been emphasised in New Keynesian models of aggregate demand and supply ${ }^{23}$ (see Svensson, 1997b, Rudebusch and Svensson, 1999, McCallum and Nelson, 1998, 1999, Rudebusch, 1999). Second, the policy rule will evolve gradually over time, as policy regime shifts are seldom sudden. To capture these variations in structure, a VAR with time-varying coefficients can be used. Muscatelli and Trecroci adopt the Bayesian VAR modelling technique suggested by Doan et al. (1984). This leads to impulse response functions that vary over time.

This procedure may be briefly described as follows ${ }^{24}$. Consider a VAR

$$
X=A Z+U,
$$

where

$$
\begin{aligned}
X & =\left(\begin{array}{llll}
X_{p+1} & X_{p+2} & \ldots & X_{T}
\end{array}\right) ; \\
A & =\left(\begin{array}{llllll}
c & A_{1} & \ldots & A_{p}
\end{array}\right) ; Z=\left(\begin{array}{llll}
Z_{p} & Z_{p+1} & \ldots & Z_{T-1}
\end{array}\right) \\
Z_{t} & =\left(\begin{array}{c}
1 \\
X_{t-1} \\
X_{t-2} \\
\vdots \\
X_{t-p}
\end{array}\right) ; U=\left(\begin{array}{lllll}
\varepsilon_{p+1} & \varepsilon_{p+2} & \ldots & \varepsilon_{T}
\end{array}\right)
\end{aligned}
$$


If we assume the VAR coefficients as time-dependent, equation $j$ in [11] can be written as:

$$
x_{t, j}=Z^{\prime}\left(\begin{array}{c}
c_{j} \\
\beta_{j 1}^{1} \\
\vdots \\
\beta_{j n}^{1} \\
\vdots \\
\beta_{j 1}^{p} \\
\vdots \\
\beta_{j n}^{p}
\end{array}\right)+u_{t, j}=Z^{\prime} \beta_{t}+u_{t, j}
$$

where the $\beta$ 's are the elements of the VAR parameter matrices. A state-space representation of such a model would have equation (12) as the measurement equation. The Doan et al. (1984) procedure assumes that the VAR coefficients follow an AR(1) process, and the following is the transition equation of the system:

$$
\beta_{t}=c+T \beta_{t-1}+v_{t}
$$

Doan et al. (1984) suggest the use of a Bayesian prior distribution for the initial value of the coefficient vector, and that the parameters should be updated according to an autoregressive process with convergence towards the mean. In practice, our results do not seem too sensitive to the choice of the prior.

The trivariate VAR is estimated for the US over the sample period 1961:3-2000:1, with the following causal ordering: output gap, inflation, and the interest rate. The output gap is defined as the percentage deviation of output from a Bureau of Economic Analysis measure of potential output. Figure 3 shows the impulse responses $^{25}$ of the federal funds rate at the first, second, third, fifth and eighthquarter horizon following unit shocks to the inflation rate over the sample period 1988-1999. Note that the response to the inflation rate shock is greater than unity, in line with MTT's single-equation forward-looking reaction function (see Section 3). Indeed, the estimated VAR policy rule highlights some of the policy changes that were apparent from the single-equation model. In 1993-94 there was a sudden tightening of US policy. This corresponds to a phase when the Fed was uncertain about the ability of the US economy to expand rapidly without inflationary consequences. Since 1995, the Fed's response to inflation shocks has been much more muted, as the Fed is responding less aggressively in the new 'productivity growth' environment. For the UK, the BVAR methodology also detects some important policy shifts. After 1992, when inflation targets were adopted, and after 1997, when the Bank of England was given instrument independence, the responsiveness of interest rates to an inflation shock increases (see Muscatell and Trecroci 2000). From MTT and Muscatell and Trecroci (200) it seems that the UK represents the one case where institutional change matters. Overall, this demonstrates that small VARs can 


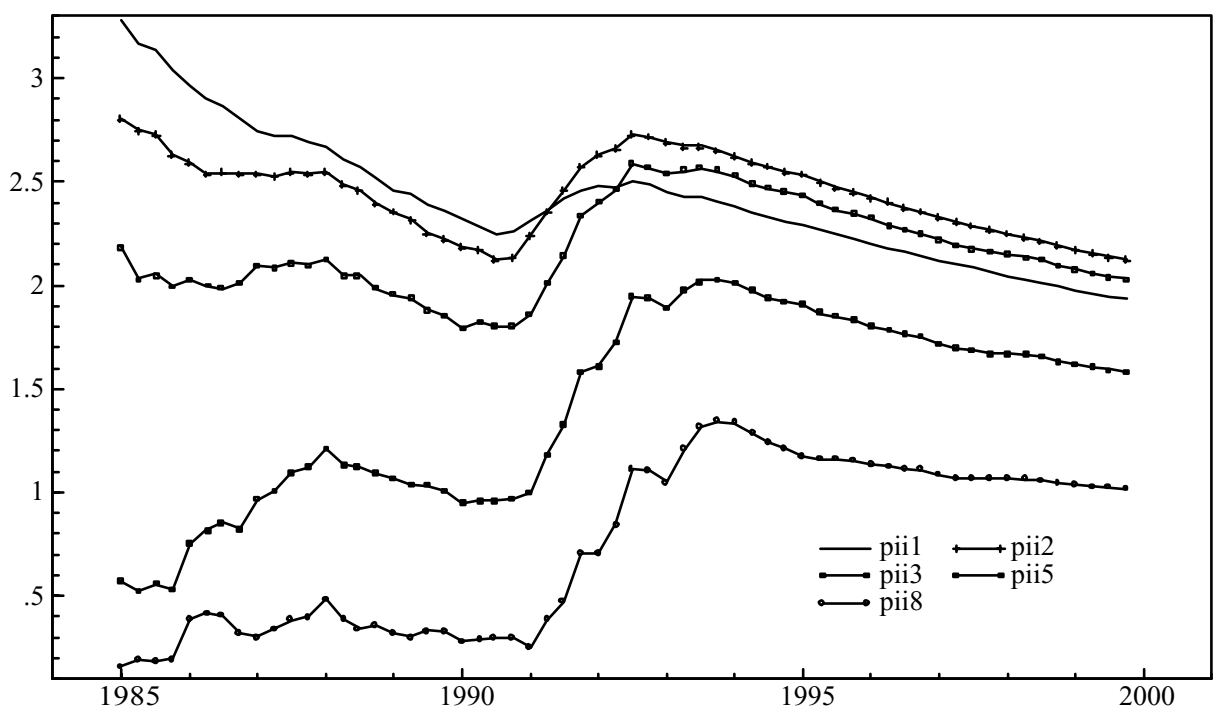

Figure 3. BVAR for the US. Effect on Interest Rate of Inflation Shock.

offer a useful vehicle to study policy responses. They also provide a useful check on single-equation estimated policy rules to ensure that the single-equation results are not an artefact of an inappropriate reduction of the model from the unrestricted reduced-form VAR.

Before concluding this section, we briefly mention another type of VAR model, which allows for policy regime shifts due to shifts in the underlying political environment. Berger and Woitek (1999) estimate a VAR model for Germany on monthly data over the period 1950:01-1994:12. The VAR is a 4variable VAR with the short-term (overnight) interest rate, M1 growth, CPI inflation, and the growth rate of industrial production. They study the response of the interest rate to the three non-policy variables by splitting the sample into periods when the Bundesbank council was dominated by different political influences (using the share of Bundesbank Council votes held by Social Democrat and Conservative nominees). They find that the reaction of the Bundesbank to inflationary shocks was less marked when non-conservatives held the majority of votes. In contrast, they find that conservative majorities on the Council led to less volatility and lower inflation. This is the only study which we are aware of which seeks to use VAR analysis whilst explicitly characterising shifts in the political environment. It also suggests that the picture of stable interest rate policy reactions for Germany which emerge from post-1980 studies (Clarida et al., 1998; Muscatelli et al., 1999, 2000) is less valid from a longer historical perspective. The problem of course is that it is difficult to reproduce this type of study on a similarly long time span for different countries to capture political cycles in macroeconomic policy. 


\section{Conclusions}

The aim of this paper has been to provide a survey of recent empirical evidence on monetary policy behaviour, and on how it relates to the literature on policy design. The main conclusions that emerge are the following. First, whilst the political economy literature emphasises the importance of institutional design for policy formulation, the empirical evidence on the importance of institutions is mixed. Cross-country evidence on the impact of institutions involves considerable problems of interpretation, and yields results which are not robust to changes in model specification. Turning to time-series evidence, if one examines the impact of institutional change on policy rules in some cases it does seem to mark a watershed in policy regime, but formal institutional reform is neither a necessary nor a sufficient condition for shifts in monetary policy rules. However, there is no doubt that in some cases (e.g. the UK following the adoption of an inflation targeting regime in 1992, and the granting of Bank of England Independence in 1997), there was a notable shift in monetary policy conduct. Second, whilst there have been interesting attempts to model policy preferences by estimating monetary policy reaction functions, our view is that there are considerable pitfalls in identifying the 'deep parameters' of political economy models of monetary policy. Third, although VAR models have not generally been used in the empirical modelling of policy preferences, we have shown that they may, in some cases, provide a useful vehicle to detect policy change. In particular, timevarying VAR models may be useful in modelling the interaction between policy shifts and changes in the transmission mechanism, as predicted by the Lucas critique.

\section{Notes}

1. The establishment of the Single Currency in Europe can be seen as an example of these dramatic changes. Recent proposals for the dollarization of devaluation-prone countries also stem from this line of reasoning.

2. And of central bankers (see Blinder, 1998, Vickers, 1999, and Bank of England, 1999).

3. Taylor (1999) collects a significant number of the most influential contributions in the area. See also McCallum (1999).

4. Debelle and Fischer's (1995) distinction between 'instrument independence' (whereby the central bank controls the policy instrument and intermediate policy objectives) and 'goal independence' (whereby the central bank also chooses the final objectives of monetary policy) turns out to be a crucial element of institutional design (see Muscatelli, 1999). The same goes for the choice of the degree of central bank transparency (see Faust and Svensson, 2000).

5. For a fuller survey of cross-country studies, see Berger et al. (2001).

6. However, the theoretical literature on monetary policy design from Rogoff (1985) to Svensson (1997a, b) clearly distinguishes between these two concepts in solving the time-inconsistency problem. CBC implies a trade-off between a lower inflation bias and output stabilisation, whilst CBI combined with inflation targets or contracts does not. However, in some instances CBI should be combined with CBC (see Berger et al., 2001). 
7. Campillo and Miron (1997) find that CBI is not correlated with average inflation once factors such as the degree of openness, or a measure of the fiscal imbalance are included in the analysis (see Berger et al. 2001)

8. See for instance Lockwood et al. (1997) and Gärtner (this issue). However, these models tend to incorporate very simple dynamics, such as an AR(1) process in the aggregate supply equation.

9. Extensions of the backward-looking interest rule in (1) have also been employed, with mixed success. These backward-looking models usually embody autoregressive terms to capture interest rate inertia. See for example (Groeneveld et al., 1998; Muscatelli and Tirelli, 1996).

10. Clarida and Gertler's (1997) reaction function included measures of expected inflation and potential output forecasts, both obtained from a previously estimated VAR model of the German economy.

11. Batini and Haldane (1999) discuss this point in detail.

12. There is a close link here with the concept of invariance in econometric models discussed in Engle and Hendry (1993).

13. Muscatelli, Tirelli, and Trecroci (2000) perform a similar exercise for four former ERM member countries in the run-up to EMU, modifying the reaction function to allow for exchange-rate stabilisation.

14. These results are not shown here for reasons of space, but are available from the authors on request. The results are probably explained by the presence of lags in the transmission of monetary policy, so that past values of the output gap are more highly correlated with inflation.

15. The constant term should be interpreted with caution. In CGG, the constant is simply interpreted as the long-run component of the real interest rate. In MTT, the constant is a function of the real interest rate, but also of the inflation target and the inflation bias.

16. The alternative interpretation is that, slowly over time, central banks have converged towards policy behaviour that is essentially close to the backward-looking Taylor rule. However, this is unlikely for two reasons. First, some central banks are explicitly reacting to inflation forecasts (e.g. the Bank of England) and yet we observe this observational equivalence for the UK in the 1990s (see Muscatelli et al., 1999). Second, this interpretation would need to explain why the Taylor rule was suddenly (and implicitly) adopted by a variety of countries from the mid-1990s — there is simply no corroborating evidence of such a policy shift.

17. See also Nelson (2000) for evidence on shifts in the UK reaction function.

18. The assumption that the structural disturbances are orthogonal is normally made, and it is a natural assumption if all the substantive features of the structural model have been adequately captured.

19. See Bernanke and Mihov (1998) for evidence in this regard.

20. For a similar approach see Uhlig (1997), and Cooley and LeRoy (1985).

21. Estimates from a monthly VAR are equally difficult to interpret; see Rudebusch (1998).

22. This critique, however, also applies to single-equation estimated policy rules.

23. For some empirical evidence for New Zealand, see Hutchison and Walsh (1998).

24. Due to lack of space, the estimation procedure cannot be set out in detail. For further details, see Muscatelli and Trecroci (2000).

25. We do not report confidence bands, because for each period and each impulse response we would need to report a confidence interval, making the graph rather difficult to read. However, having checked the impulse responses and confidence

(C) Blackwell Publishers Ltd. 2000 
intervals (constructed using bootstrap methods) for critical periods discussed in the text, when the policy regimes were subject to change, we can confirm that the impulse responses discussed are significantly different from zero at the $95 \%$ confidence. Detailed results are available on request from the authors.

\section{References}

Alesina, A. and Summers, L. (1993) Central Bank Independence and Macroeconomic Performance. Journal of Money, Credit and Banking, 20, 1, pp. 63-82.

Amato, J. D. and Laubach, T. (1999) Forecast-based Monetary Policy. Mimeo, BIS.

Bagliano, F. C., Favero, C. A. (1998) Measuring monetary policy with VAR models: An evaluation. European Economic Review, 42, 6, 1069-1112.

Barro, R. J. and Gordon, D. B. (1983) A positive theory of monetary policy in a natural rate model. Journal of Political Economy, 91, pp. 589-610.

Bank of England (1999) Economic Models at the Bank of England. Bank of England.

Batini, N. and Haldane, A. G. (1998) Forward-looking rules for monetary policy. In Taylor (1999).

Berger, H. and Woitek, U. (1999) Does Conservatism Matter? A Time Series Approach to Central Banking. University of Glasgow, Discussion Papers in Economics, No 9814, CESifo Working Paper No 190.

Berger, H., de Haan, J. and Eijffinger, S. C. W. (2001) Central Bank Independence: an Update of Theory and Evidence. Journal of Economic Surveys, forthcoming.

Bernanke, B. S. and Mihov, I. (1997) What Does the Bundesbank Target? European Economic Review, 41, 6, 1025-1053.

Bernanke, B. S. and Mihov, I. (1998) Measuring Monetary Policy. Quarterly Journal of Economics, 113, 3, pp. 869-902.

Bernanke, B. S., Gertler, M. and Gilchrist, S. (1999) The financial accelerator in a quantitative business cycle framework. In J. B. Taylor and M. Woodford (eds), Handbook of Macroeconomics, vol. 1c, pp. 1341-1393. Elsevier.

Blanchard, O. J. (1990) Why does money affect output? A survey. In B. M. Friedman and F. H. Hahn (eds), Handbook of Monetary Economics, vol. II, pp. 779-835.

Blanchard, O. J. and Quah, D. (1989) The dynamic effects of aggregate demand and supply disturbances. American Economic Review, vol. 79, pp. 655-673.

Blinder, A. S. (1998) Central banking in theory and practice. MIT, Cambridge, Mass.

Calvo, G. A. (1983) Staggered prices in a utility-maximizing framework. Journal of Monetary Economics, 12, 383-398.

Campillo, M. and Miron, J. (1997) Why Does Inflation Vary across Countries? In Romer and Romer (eds) (1997).

Canova, F. (1995) Vector autoregressive models: specification, estimation, inference and forecasting. In M. H. Pesaran and M. Wickens (eds), Handbook of applied econometrics: Macroeconomics. Blackwell, Oxford.

Chinn, M. D. and Dooley, M. P. (1997) Monetary Policy in Japan, Germany and the United States: does one size fit all? NBER Working Paper \#6092.

Christiano, L. J. and Gust, C. J. (1999) Taylor rules in a limited participation model. NBER Working Paper \#7017.

Christiano, L. J., Eichenbaum, M. and Evans, C. L. (1996) Identification and the effects of monetary policy shocks. In M. I. Blejer et al. (eds), Financial factors in economic stabilization and growth. Cambridge; New York and Melbourne: Cambridge University Press, pp. 36-74.

Christiano, L. J., Eichenbaum, M. and Evans, C. L. (1997) Sticky price and limited participation models of money: a comparison. European Economic Review, 41, pp. 1201-1241.

(C) Blackwell Publishers Ltd. 2000 
Christiano, L. J., Eichenbaum, M. and Evans, C. L. (1998) Monetary Policy Shocks: What Have We Learned and to What End? NBER Working Paper \# 6400.

Clarida, R. and Gertler, M. (1997) How the Bundesbank Conducts Monetary Policy. In C. D. Romer and D. H. Romer (eds), Reducing Inflation: Motivation and Strategy. NBER, University of Chicago Press.

Clarida, R., Gali, J. and Gertler, M. (1998) Monetary policy rules in practice: some international evidence. European Economic Review, vol. 42, no. 6, pp. 1033-1067.

Cooley, T. and LeRoy, S. (1995) Atheoretical macroeconomics: a critique. Journal of Monetary Economics, vol. 16, pp. 283-308.

Cukierman, A. (1992) Central Bank Strategy, Credibility and Independence: Theory and Evidence. MIT Press, Cambridge MA.

Cukierman, A., Webb, S. and Neyapti, B. (1992) Measuring the independence of Central Banks and its Effects on Policy Outcomes. The World Bank Economic Review, 6 (3), pp. $353-398$.

Debelle, G. and Fischer, S. (1995) How independent should a central bank be? In J. C. Fuhrer (ed.), Goals, guidelines and constraints facing monetary policymakers, Federal Reserve Bank of Boston, Conference Series n. 38, pp. 195-221.

Doan, T., Litterman, R. and Sims, C. (1984) Forecasting and conditional projections using realist priori distributions. Econometric Reviews, 3(1), 1-100.

Drazen, A. (2000) Political Economy in Macroeconomics. Princeton University Press.

Eijffinger, S. C. W. and de Haan, J. (1996) The political economy of central-bank independence. Princeton University, Department of Economics, International Finance Section, Special Papers in International Economics \# 19.

Engle, R. F. and Hendry, D. F. (1993) Testing superexogeneity and invariance in regression models. Journal of Econometrics, vol. 56, pp. 119-39.

European Central Bank (1999) The stability-oriented monetary policy strategy of the Eurosystem. ECB Monthly Bulletin, January, pp. 39-50.

Faust, J. (1998) The robustness of identified VAR conclusions about money. CarnegieRochester Conference Series, 19, 207-44.

Faust, J. and Svensson, L. E. O. (2000) Transparency and credibility: monetary policy with unobservable goals. Forthcoming, International Economic Review.

Favero, C. and Rovelli, R. (1999) Modelling and identifying central banks' preferences. CEPR Discussion Paper n.2178.

Gärtner, M. (2000) Political macroeconomics: a survey of recent developments. Journal of Economic Surveys, this issue.

Gerlach, S. and Schnabel, G. (2000) The Taylor rule and interest rates in the EMU area: a note. Economics Letters, vol. 67, 2, 165-171.

Gerlach, S. and Smets, F. (1999) Output gaps and monetary policy in the EMU area. European Economic Review, 43, pp. 801-812.

Goodhart, C. A. E. (1996) Why do the monetary authorities smooth interest rates? LSE Financial Markets Group Special Paper, 81, February.

Goodhart, C. A. E. (1999) Central bankers and uncertainty. Bank of England Quarterly Bulletin, February 1999, pp. 102-21.

Grilli, V., Masciandaro, D. and Tabellini, G. (1991) Political and monetary institutions and public financial policies in the industrial countries. Economic Policy, October, pp. 342-92.

Groeneveld, H., Koedijk, K. G. and Kool, C. J. M. (1998) Inflation dynamics and monetary strategies: evidence from six industrialised countries. Open Economies Review, 9, 1, pp. 21-38.

Harvey, A. C. (1989) Forecasting, Structural Time Series Models and the Kalman Filter. Cambridge University Press: Cambridge.

Hutchison, M. M. and Walsh, C. E. (1998) The output-inflation tradeoff and central bank reform: evidence from New Zealand. The Economic Journal, 108, 703-725. 
Kim, C.-J. and Nelson, C. R. (1999) State-space models with regime switching. MIT Press, Cambridge Mass.

Kydland, F. E. and Prescott, E. C. (1977) Rules rather than discretion: the inconsistency of optimal plans. Journal of Political Economy, 85, 3, pp. 473-491.

Laubach, T. and Posen, A. (1997) Some Comparative Evidence on the Effectiveness of Inflation Targeting. FRBNY Research Paper n.9714.

Leeper, E. M., Sims, C. A. and Zha, T. (1996) What Does Monetary Policy Do? Brookings Papers on Economic Activity, No. 2.

Lockwood, B., Miller, M. and Zhang, L. (1997) Central Banks and Reputation: Some Transatlantic Contrasts, mimeo., University of Warwick.

McCallum, B. T. (1999) Issues in the design of monetary policy rules. In J. B. Taylor and M. Woodford (eds), Handbook of Macroeconomics, vol. 1c, pp. 1481-1530. Elsevier.

McCallum, B. T. and Nelson, E. (1998) Performance of Operational Policy Rules in an Estimated Semi-Classical structural Model. NBER Working Paper \# 6599.

McCallum, B. T. and Nelson, E. (1999) Nominal income targeting in an open-economy optimising model. Journal of Monetary Economics, vol. 43, pp. 553-78.

Mishkin, F. S. (1999) International Experiences with Different Monetary Policy regimes. Journal of Monetary Economics, 43, pp. 579-605.

Mishkin, F. S. and Posen, A. S. (1997) Inflation Targeting: Lessons from Four Countries. NBERWorking Paper \#6126.

Muscatelli, V. A. (1998a) Optimal Inflation Contracts and Inflation Targets with Uncertain Central Banks Preferences: Accountability through Independence? The Economic Journal, 108, 529-542.

Muscatelli, V. A. (1998b) Political Consensus, uncertain preferences and central bank independence. Oxford Economic Papers, 1998, 50, 412-430.

Muscatelli, V. A. (1999) Inflation Contracts and Inflation Targets under Uncertainty: Why we Might Need Conservative Central Bankers? Economica, vol. 66, pp. 241-54.

Muscatelli, V. A. and Tirelli, P. (1996) Institutional change, inflation targets and the stability of interest rate functions in OECD economies. University of Glasgow Dept. Of Economics Discussion Paper \# 9606.

Muscatelli, A., Tirelli, P. and Trecroci, C. (1999) Does institutional change really matter? Inflation targets, central bank reform and interest rate policy in the OECD countries. CES-ifo Working Paper \#278, Munich.

Muscatelli, A., Tirelli, P. and Trecroci, C. (2000) Monetary Policy on the Road to EMU: the Dominance of External Constraints on Domestic Objectives. University of Glasgow, Discussion Papers in Economics \#2000-8.

Muscatelli, A. and Trecroci, C. (2000) Central Bank Goals, Institutional Change and Monetary Policy: Evidence from the US and UK. Mimeo, University of Glasgow, June.

Nelson, E. (2000) UK Monetary policy 1972-97: a guide using Taylor rules. Mimeo. Bank of England, March.

Onatski, A. and Stock, J. H. (2000) Robust monetary policy under model uncertainty in a small model of the US economy. NBER Working Paper \#7490.

Orphanides, A. (1999) The Quest for Prosperity without Inflation. Mimeo, Board of Governors of the Federal Reserve System.

Peersman, G. and Smets, F. (1999) Uncertainty and the Taylor Rule in a simple model of the euro-area economy. International Finance, 2:1, 85-116.

Persson, T. and Tabellini, G. (1999) Political Economics and macroeconomic policy. In Taylor, J. B. and Woodford, M. (eds), Handbook of Macroeconomics, vol. 1c, pp. 1397-1482. Elsevier.

Piga, G. (2000) Dependent and accountable: evidence from the mdoern theory of central banking. Journal of Economic Surveys, this issue.

Posen, A. S. (1993) Why central bank independence does not cause low inflation: there is no

(C) Blackwell Publishers Ltd. 2000 
institutional fix for politics. In R. O'Brien (ed.), Finance and the International Economy, Oxford University Press, pp. 40-65.

Posen, A. S. (1995) Declarations are not enough: Financial sector services and central bank independence. In B. Bernanke and J. Rotemberg, NBER Macroeconomics Annual, 1995, Cambridge MIT Press.

Rogoff, K. (1985) The optimal commitment to an intermediate monetary target. Quarterly Journal of Economics, 100, 4, 1169-1189.

Rotemberg, J. J. (1983) Supply shocks, sticky prices and monetary policy. Journal of Money, Credit and Banking, 27(4) 975-984.

Rotemberg, J. J. and Woodford, M. (1999) Interest-rate rules in an estimated sticky price model. In Taylor (1999), pp. 57-119.

Rudebusch, G. D. (1998) Do measures of monetary policy in a VAR make sense? International Economic Review, vol. 39, pp. 907-31.

Rudebusch, G. D. and Svensson, L. E. O. (1999) Policy rules for inflation targeting. In Taylor (1999)

Rudebusch. G. D. (1999) Assessing Nominal Income Rules for Monetary Policy with Model and Data Uncertainty. Mimeo, Federal Reserve Bank of San Francisco.

Sims, C. A. (1980) Macroeconomics and reality. Econometrica, 48, 1-48.

Sims, C. A. (1996) Comment on Glenn Rudebusch's 'Do measures of monetary policy in a VAR make sense?' International Economic Review, 39, 933-41.

Svensson, L. E. O. (1997a) Optimal Inflation Targets, Conservative Central Banks and Linear Inflation Contracts. American Economic Review, 87, 98-114.

Svensson, L. E. O. (1997b) Inflation-forecast-targeting: implementing and monitoring inflation targets. European Economic Review, 41, 1111-1146.

Svensson, L. E. O. (2000) Open-economy inflation targeting. Journal of International Economics, 50, pp. 155-183.

Svensson, L. E. O. and Woodford, M. (1999) Implementing Optimal Policy through Inflation-Forecast Targeting. Mimeo, Princeton University.

Svensson, L. E. O. and Woodford, M. (2000) Indicator Variables for Monetary Policy. ECB Working Paper \#12.

Taylor, J. B. (1993) Discretion versus policy rules in practice. Carnegie-Rochester Series on Public Policy, 39, pp. 195-214.

Taylor, J. B. (ed.) (1999) Monetary Policy Rules. University of Chicago Press.

Uhlig, H. (1997) What are the effects of monetary policy? Results from an agnostic identification procedure. Miemo, Tilburg University.

Vickers, J. (1999) Economic models and monetary policy. Speech to the Governors of the NIESR, 18 March 1999.

Walsh, C. E. (1998) Monetary Theory and Policy. MIT, Cambridge, Mass.

Woodford, M. (1999) Optimal monetary policy inertia. NBER Working Paper \#7261.

\section{Appendix A}

In this Appendix we follow Muscatelli et al. (1999), and derive a forward-looking interest rate reaction function from a standard model of monetary policy design. Consider the following model for current inflation in the presence of costly priceadjustment as in Calvo (1983) or Rotemberg (1983) (Rotemberg and Woodford, 1999, propose a sticky-price model which has similar implications):

$$
\pi_{t}=p_{t}-p_{t-1}=\beta \pi_{t+1}^{e}+\varphi\left(y_{t}-y^{*}\right)
$$

(C) Blackwell Publishers Ltd. 2000 
where current inflation, $\pi$ depends on inflation expectations and the current output gap, where $y^{*}$ is potential output. The output gap is given by:

$$
y_{t}-y^{*}=-s\left[R_{t}-R_{t}^{e}\right]+\varepsilon_{t}
$$

Lags in the transmission mechanism could be easily introduced in (A.2), and this would simply complicate the lag structure of the policy rule. Output deviations from the natural rate depend on a supply shock, $\varepsilon_{t}$, and the deviations of the nominal interest rate $R_{t}$ (which is the policy instrument), from its expected value, $R_{t}^{e}$.

$$
R_{t}^{e}=r^{*}+\pi_{t+1}^{e}
$$

where $r^{*}$ is the (ex ante) real interest rate.

Following Svensson (1998), suppose that the monetary policy-maker's loss function is given by:

$$
L=\chi\left(\pi_{t}-\pi^{*}\right)+\left(y_{t}-\tilde{y}\right)^{2}+\rho\left[R_{t}-E\left(R_{t}\right)\right]^{2}+\rho_{1}\left(R_{t}-R_{t-1}\right)^{2}
$$

where the authorities penalise not only deviations of output from an output target, $\tilde{y}$, which exceeds the natural level $y^{*}$ (as in Barro and Gordon, 1983), and of inflation from a target $\pi^{*}$ (as in Svensson, 1997a), but also penalise changes and deviations in the policy instrument.

This formulation assumes that stabilisation policy via interest rate changes is costly, and that for this reason shocks are never fully stabilised in the long run. Svensson's (1997a) model highlights the risk of instability of an anti-inflationary policy by assuming that the policymaker penalises deviations of $R_{t}$ from zero. Instead the formulation in (A.4) assumes that the policymaker knows the level of inflationary expectations, and consequently chooses a sequence for $R_{t}$. However, in the event of shocks hitting the economy, the authority decides whether to deviate from the nominal interest rate implied by the state of inflationary expectations. Solving the model under discretion, so that the monetary authority minimises (A.4) with respect to the nominal interest rate, taking expectations as given, yields an interest rate reaction function:

$$
R_{t}=w r^{*}-A^{*}+b^{*} \pi_{t+1}^{e}+c^{*} \varepsilon_{t}+d^{*} R_{t-1}
$$

where the coefficients are:

$$
\begin{aligned}
w & =\frac{s^{2} \varphi^{2} \chi+s^{2}}{\left[s^{2} \varphi^{2} \chi+s^{2}+\rho_{1}\right]} ; \quad b^{*}=\frac{s^{2} \varphi^{2} \chi+s^{2}+\chi \beta \varphi s}{\left[s^{2} \varphi^{2} \chi+s^{2}+\rho_{1}\right]} ; \\
c^{*} & =\frac{s \varphi^{2} \chi+s}{\left[s^{2} \varphi^{2} \chi+s^{2}+\rho+\rho_{1}\right]} ; \quad d^{*}=\frac{\rho_{1}}{\left[s^{2} \varphi^{2} \chi+s^{2}+\rho_{1}\right]} \\
A^{*} & =\frac{s\left(\tilde{y}-y^{*}\right)+\chi \varphi s \pi^{*}}{\left[s^{2} \varphi^{2} \chi+s^{2}+\rho_{1}\right]}
\end{aligned}
$$


This is similar to equation (2) in the main text. Note that we need the interest rate adjustment costs $\rho_{1}$ to be not too large to avoid an unstable system following output shocks, as current inflation depends on expected future inflation. ${ }^{1}$ It is also important to note that, in when one estimates a reaction function such as (A.5), the interpretation of the constant is different from that in Clarida et al. (1998). Basically, (A.5) implies that the constant $\left(w r^{*}-A^{*}\right)$ is a function of the real interest rate, inflation target and inflationary bias, while in Clarida et al. it is referred to as simply the long-run component of the real interest rate. This demonstrates that one has to be careful in interpreting the estimated parameters of an interest rate reaction function, as these largely depend on the assumptions one makes about the monetary authorities' loss function. In practice it is difficult to identify the authorities' policy preferences from estimated reaction functions.

${ }^{1}$ In general the system will be stable as long as $\chi \beta \varphi s>\rho_{1}$, which implies $b^{*}>1$, and that the expected inflation response to the output gap is positive. Under RE the reaction function in (A.5) yields the following equilibrium inflation rate:

$$
\pi_{t}=\left[\frac{\beta \rho_{1}}{\chi \beta \varphi s-\rho_{1}}\right] r^{*}+\frac{\beta\left[s\left(\tilde{y}-y^{*}\right)+\chi \varphi s \pi^{*}\right]}{\chi \beta \varphi s-\rho_{1}}-\left[\frac{\beta \rho_{1}}{\chi \beta \varphi s-\rho_{1}}\right] R_{t-1}+\varphi\left(1-s c^{*}\right) \varepsilon_{t}
$$

(C) Blackwell Publishers Ltd. 2000 